\title{
O contexto geográfico e ambiental das Áreas de Preservação Permanente
}

\author{
El contexto geográfico y ambiental de las áreas de preservación \\ permanente
}

\section{The geographic and environmental context of permanent preservation areas}

\author{
Alexei Nowatzki \\ nowatzki.a@gmail.com \\ Doutorando em Geografia - Universidade Federal do Paraná \\ Orestes Jarentchuk Junior \\ jarentchuk@hotmail.com \\ Doutorando em Geografia - Universidade Federal do Paraná \\ Eduardo Vedor de Paula \\ eduardovedordepaula@yahoo.com.br \\ Departamento de Geografia - Universidade Federal do Paraná
}

Resumo: Neste ensaio objetivou-se discutir de que maneira alguns conceitos geográficos estão inseridos na discussão da Lei Florestal Brasileira, sobretudo na definição das Áreas de Preservação Permanente (APPs). Para realizar tal meta, foi discutido sobre como a perspectiva sistêmica integra os elementos do meio físico, por meio do recorte espacial da bacia hidrográfica que serve como unidade de análise dessas áreas de preservação. Também foi destacada a funcionalidade ambiental da APPs as margens de rios e nascentes.

Palavras-chave: Lei Florestal Brasileira. Sistema. Paisagem. Território.

Resumen: Este ensayo tuvo como objetivo discutir cómo se incluyen algunos conceptos geográficos en la discusión de la Ley Forestal de Brasil, principalmente en la definición de Âreas de Preservación Permanente (APPs). Para lograr este objetivo, se discutió sobre cómo el enfoque sistémico integra los elementos del medio físico, por medio del estudio espacial de la cuenca hidrográfica que sirve de base para el análisis de estas áreas de conservación. También se destacó la funcionalidad ambiental de las APPs en los márgenes de ríos y nacientes.

Palabras-clave: Ley Forestal de Brasil. Sistema. Paisaje. Territorio.

Abstract: This essay aimed to discuss how some geographic concepts are included in the discussion of the Brazilian Forestry Law, especially in the definition of Permanent Preservation Areas (APPs). To accomplish this goal, it was discussed about how the systemic approach integrates the elements of the physical environment, through the watershed's spatial area that serves as the basis for the analysis of these preservation 
areas. It was also highlighted the environmental functionality of APPs at riversides and springs.

Keywords: Brazilian Forestry Law. System. Landscape. Territory.

\section{INTRODUÇÃO}

No Brasil, os mecanismos legais associados à preservação do meio ambiente entraram em vigor com o Código Florestal Brasileiro. Dentro deste quadro, as Áreas de Preservação Permanentes (APPs) são consideradas espaços físicos legalmente protegidos, pois estas áreas devem manter sua cobertura vegetal nativa, conforme o bioma em que as mesmas se inserem.

O primeiro Código Florestal foi promulgado em 1934, e em 1965 foi revogado pela Lei ${ }^{\circ} 4.771$, com os critérios para determinação de APPs claramente definidos nos termos dos Artigos $2^{\circ}$ e $3^{\circ}$. Esta lei passou por atualizações nos primeiros anos deste século, a partir da publicação de-Medidas Provisórias, Leis e Resoluções CONAMA. Sua última versão foi instituída em 2012 a partir da Lei n 12.651, no dia 25 de maio, que por sua vez passou por atualizações com a Lei $n^{\circ} 12.727$, de 17 de outubro do mesmo ano.

Estas áreas de preservação têm, de um modo geral, a função ambiental de preservar os recursos hídricos, a paisagem, a estabilidade geológica, a biodiversidade, o fluxo gênico de fauna e flora, proteger o solo e assegurar o bem-estar das populações humanas (BRASIL, 2012). Nesse sentido, é de suma importância sua manutenção, pois as APPs prestam serviços ecossistêmicas, sobretudo as categorias de matas ciliares de rios e nascentes.

Em paisagens com a vegetação natural fragmentada, as matas ciliares funcionam como corredores ecológicos, promovendo a conectividade entre os fragmentos e facilitando o deslocamento de espécies animais e vegetais ao longo da paisagem. Muitas aves florestais não têm a capacidade de atravessar áreas abertas, mesmo no caso de pequenos trechos sem floresta, como estradas, por exemplo. Para essas espécies os corredores têm função essencial na dispersão através da paisagem, contribuindo deste modo à conservação da biodiversidade (DEVELEY; PONGILUPPI, 2010).

A legitimidade da importância da manutenção das APPs é proporcional aos serviços que elas prestam ao ambiente em que se inserem. Assim, constituem-se em locais com grande relevância ambiental, nos quais seus recursos naturais devem estar constantemente preservados em suas condições ambientais originais (NOWATZKI; SANTOS: PAULA, 2010).

Varjabedian e Mechi (2013) destacam a necessidade de proteção especial para outras categorias de APPs, como topos de morro, montanhas e/ou serras. Os autores salientam que nos espaços ocupados pelos componentes bióticos e abióticos das APPs, em interação, estes cumprem funções ecológicas indispensáveis para a persistência de todas as formas de vida, ou seja, cumprem diversas funções ambientais imprescindíveis para o desenvolvimento de processos ecológicos essenciais.

Neste contexto, objetivou-se discutir sobre a pertinência da utilização de conceitos inerentes à ciência geográfica, tais como Paisagem e Território, que auxiliem na compreensão 
da importância das APPs no contexto socioambiental, e aparecem implicitamente nos discursos acerca da legislação ambiental. Foi destacada também a perspectiva sistêmica, pois a partir dela é possível entender de maneira integral os elementos ou componentes do meio físico e sua interligação, bem como legitimar a adoção de uma bacia hidrográfica como recorte espacial para a delimitação de APPs. Por fim, efetuou-se uma análise referente às funcionalidades ambientais dessas áreas.

\section{A PERSPECTIVA SISTÊMICA E O USO DAS BACIAS HIDROGRÁFICAS COMO RECORTE ESPACIAL PARA A ANÁLISE DAS APPs}

O termo sistema, preconizado por Ludwig von Bertalanffy na primeira metade do século XX a partir da Teoria Geral dos Sistemas, pode ser usado como suporte para o entendimento de aspectos físicos/naturais do espaço geográfico. Para Mendonça (1993), este conceito aplica-se aos estudos relativos à Geografia Física, considerando a unidade bacia hidrográfica como um sistema aberto e que pode ser tratado de maneira eficaz no tocante à análise quantitativa e qualitativa do fluxo de matéria e energia que nele se processa.

Christofoletti (1980, p.1) salienta que "um sistema pode ser definido como o conjunto dos elementos e das relações entre si e entre os seus atributos", e de acordo com o autor, alguns aspectos devem ser abordados nesta temática, tais como matéria, energia e estrutura. Para este autor, uma ação humana pode influenciar diversas mudanças na distribuição destes aspectos dentro dos sistemas, modificando assim o equilíbrio dos mesmos. Outrossim, Tricart (1977) explica o sistema como um conjunto de fenômenos que se processam mediante fluxos de matéria e energia. Segundo o autor, esses fluxos originam relações de dependência mútua entre os fenômenos. Consequentemente, o sistema apresenta propriedades que lhe são inerentes e diferem da soma das propriedades dos seus componentes, e uma delas é ter dinâmica própria. O mesmo autor adverte que o conceito de sistema é o melhor instrumento lógico para estudar os problemas do ambiente. Ele permite adotar uma atitude dialética entre a necessidade da análise e a necessidade-de uma visão de conjunto, capaz de ensejar uma atuação eficaz sobre esse ambiente. Este conceito é, por natureza, de caráter dinâmico e por isso adequado a fornecer os conhecimentos básicos para uma atuação.

Para Tricart (1977) o termo Ecossistema, utilizado originalmente apenas pela Ecologia, já vinha sendo aplicado na Geografia Física com cunho ambiental como um todo. A adoção do conceito ecológico, usando-se o instrumental lógico dos sistemas, permite estudar as relações entre os diversos componentes do ambiente. "Podemos reequilibrar, dialeticamente, nosso pensamento cientifico, alterado e viciado pelo excesso unilateral da análise" (TRICART, 1977, p.28).

Para o âmbito da Geografia, adotou-se na década de 1970 o conceito de Geossistema, que para Sotchava (1976) aborda os fatores naturais considerando-os em interface com fatores econômicos e sociais, com caráter dinâmico e interativo. Deste modo, o homem passou a ser visto como um ser social no sistema, e não mais como apenas um ser biológico. É nesse 
contexto que se pode compreender a composição do ambiente, a partir da interrelação dos meios físico, biótico e socioeconômico (antrópicos), exigindo uma visão sistêmica para a análise ambiental, como bem aponta Leff (2001). O autor, em seu trabalho de epistemologia ambiental, propõe o raciocínio acerca das condições teóricas e do estabelecimento de métodos que orientem as práticas interdisciplinares, a partir de um pensamento holístico para a reconstituição de uma realidade total.

Assim, com o intuito de compreender as dinâmicas naturais, deve-se primeiramente estudá-las como se o homem não interferisse nestes fluxos, ainda que na atualidade já não existam ecossistemas intocados pelo homem (LEFF, 2001). Uma atitude intelectual, mais objetiva, para a conservação ou planejamento, consiste em distinguir uma situação inicial como se fora livre de toda a intervenção.

Partindo desta perspectiva, Ross (2003) mostra que as relações de troca energética entre as partes criam uma situação de absoluta interdependência, não permitindo, por exemplo, o entendimento da dinâmica e da gênese do relevo sem que se conheça o clima, os solos, a litologia e seus respectivos arranjos estruturais. Ou ainda, a análise da fauna deve estar associada à flora que lhe dá suporte e que, por sua vez, não pode ser entendida sem o conhecimento do clima, da dinâmica hídrica, dos tipos de solos e assim sucessivamente. Ross (2003) argumenta também que as sociedades humanas não devem ser tratadas como elementos estranhos à natureza e, portanto, aos sistemas ambientais onde vivem.

De acordo com Cunha e Guerra (2003), os desequilíbrios ambientais originam-se, muitas vezes, da visão setorizada dentro de um conjunto de elementos que compõe a paisagem. A bacia hidrográfica, como unidade integradora desses setores (naturais e sociais), deve ser administrada com esta função a fim de que os impactos ambientais sejam minimizados. Para os mesmos autores, as bacias hidrográficas contíguas, de qualquer hierarquia, estão interligadas pelos divisores topográficos, formando uma rede de drenagem, o qual transporta material sólido e dissolvido para um ponto terminal. Este pode ser outro rio, de hierarquia igual ou superior, lago, reservatório, ou oceano. Christofoletti (1980) adverte que os rios são os agentes mais importantes no transporte de materiais intemperizados das áreas elevadas para as mais baixas.

A rede de drenagem é considerada por Cunha e Guerra (2003) um sistema aberto com entradas e saídas de energia. As bacias de drenagem, para os mesmos autores, recebem energia fornecida pela atuação do clima e da tectônica locais, eliminando fluxos energéticos pela saída da água, sedimentos e solúveis. Internamente, verificam-se constantes ajustes nos elementos das formas e nos processos associados, em função das mudanças de entrada e saída de energia. De fato, as bacias hidrográficas podem ser compreendidas como unidades sistêmicas, as quais delimitam determinadas áreas da superfície terrestre a partir de uma rede de drenagem, com direcionamento de fluxo d'água e carreamento de materiais particulados para uma saída comum (COELHO NETTO, 2007).

Para o mapeamento de APPs, portanto, é possível aplicar a perspectiva sistêmica, desde que as compreendamos como uma variável a ser inter-relacionada com outros elementos do meio físico, cumprindo a proposição da Lei Florestal Brasileira (BRASIL, 2012) no que diz respeito a atingir um equilíbrio natural como um todo e o bem-estar da sociedade. 
Segundo apontamentos de Magalhães e Ferreira (2000), as APPs podem ser consideradas como uma variável para a manutenção do equilíbrio do ciclo hidrológico em uma bacia hidrográfica e, nesse sentido, é válida a adoção de bacias hidrográficas como recortes espaciais de mapeamento de APPs. Como exemplo pode-se citar Paula, Guimarães e Ibaixe (2014) que, visando a redução dos custos com o tratamento de água para o abastecimento do município de Jaguariúna (SP), efetuaram a estimativa da atual produção de sedimentos na bacia hidrográfica do rio Jaguari (SP/MG), bem como realizaram a estimativa da potencial redução desta produção em um cenário de restauração florestal de APPs. Outro projeto que merece destaque refere-se ao RAPPs (Recuperação de Áreas de Preservação Permanente), o qual está em desenvolvimento nas bacias hidrográficas dos rios Pequeno e Cachoeira (Antonina, PR) com o objetivo de apoiar a restauração das APPs degradadas, por meio da implantação do CAR (Cadastro Ambiental Rural) e do SAFs (Sistemas Agroflorestais), conforme descrevem Santos e Boldrini (2012).

Inúmeros diagnósticos voltados à elaboração de instrumentos de planejamento e gestão ambiental do território, ao adotarem a bacia hidrográfica como unidade de análise, também efetuaram a avaliação do grau de degradação das APPs como estratégia de priorização de áreas a serem recuperadas, visando o reestabelecimento das funcionalidades ambientais. Como exemplos podem-se referenciar o Plano Municipal de Gestão de Recursos Hídricos de Cerro Azul, PR (PAS, 2009) e o diagnóstico do Plano de Manejo da APA Federal de Guaraqueçaba (UFPR, 2014).

Na perspectiva de caracterizar a dinâmica de uso do solo e dos problemas ambientais associados, no entorno de empreendimentos em processos de licenciamento ambiental, as equipes interdisciplinares responsáveis pela elaboração dos Estudos de Impacto Ambientais (EIAs) têm adotado essa mesma estratégia. Os profissionais e/ou pesquisadores avaliamo grau de conservação das APPs, geralmente delimitadas nas Áreas de Influência Direta dos empreendimentos, as quais predominantemente são correspondentes aos limites de bacias hidrográficas, ou mesmo áreas incrementais de drenagem. Para exemplificar essa abordagem pode-se mencionar trabalhos como o EIA dos terminais portuários de Paranaguá, PR (ACE, 2013) e de Pontal do Paraná, PR (ACE, 2014).

No tocante ao mapeamento das APPs, Nowatzki, Santos e Paula (2010) propuseram uma metodologia de como utilizar o SIG (Sistema de Informação Geográfica) para mapear as diversas categorias dessas áreas na bacia hidrográfica do rio Sagrado (Morretes, PR). Noutro momento, Nowatzki e Santos (2012), fizeram uma análise das APPs das bacias dos rios Sagrado e Alto Cachoeira, com destaque ao grau de preservação e d/ou degradação dessas áreas, conforme o reconhecimento da cobertura vegetal e uso da terra para dois anos distintos. Almeida, Paula e Kleina (2014), a partir desse trabalho, revisaram as APPs do rio Sagrado a fim de destacar as modificações ocorridas com as mudanças na Lei Florestal de 2012. 


\section{AS ÁREAS DE PRESERVAÇÃO PERMANENTE NO CONTEXTO DE PAISAGEM}

As APPs são áreas que podem ser entendidas através do conceito geográfico de Paisagem. Schier (2003) coloca a ideia de que, tradicionalmente, os geógrafos diferenciam a paisagem natural da paisagem cultural. A paisagem natural refere-se aos elementos combinados de terreno, vegetação, solo, rios e lagos, enquanto a paisagem cultural, humanizada, inclui todas as modificações feitas pelo homem, como nos espaços urbanos e rurais. De modo geral, o estudo da paisagem exige a seleção do enfoque no qual se pretende fazer a avaliação, definindo o conjunto dos elementos envolvidos, bem como a escala a ser considerada e a temporalidade na paisagem.

As APPs estão inseridas na paisagem e, por conseguinte, numa série de fluxos energéticos e materiais, tornando esta discussão especificamente geográfica. Georges Bertrand (2004) entende a Paisagem por meio de conexões dinâmicas (ou sistêmicas) e através das inter-relações dos elementos bióticos e abióticos que nela estão presentes:

“(...) a paisagem não é a simples adição de elementos geográficos disparatados. É, em uma determinada porção do espaço, o resultado da combinação dinâmica, portanto instável, de elementos físicos, biológicos e antrópicos que, reagindo dialeticamente uns sobre os outros, fazem da paisagem um conjunto único e indissociável, em perpétua evolução". (BERTRAND, 2004, p.1).

Sob um raciocínio similar, Sauer (1998, apud SCHIER 2003) destaca que essa interação dos elementos naturais e antrópicos é essencial no entendimento da paisagem. Para ele, não é possível formar uma ideia de paisagem a não ser em termos de suas relações associadas ao tempo, bem como suas relações vinculadas ao espaço. Portanto, a paisagem está em um processo constante de desenvolvimento ou dissolução e substituição. Assim, no sentido corológico, a alteração da área modificada pelo homem e sua apropriação para o uso são de importância fundamental. A área anterior à atividade humana é representada por um conjunto de fatos morfológicos, enquanto as formas que o homem introduziu são um conjunto distinto destes fatos.

Embora as APPs sejam áreas dotadas também com uma função social, ao tratar da preservação dos recursos naturais, ao senso comum, torna-se difícil compreender as paisagens com APPs respeitadas como paisagens culturais. Quando delimitadas num raio mínimo de $50 \mathrm{~m}$ em torno do local de surgência (BRASIL, 2012), esta paisagem possui a aparência de vegetação em seu estado natural, podendo assim ser entendida como uma área que mantém características de uma Paisagem Natural. Entretanto, a partir do momento em que o observador percebe tratar-se de um recorte criado com a intenção de preservar um recurso natural - a água - este passa a ter uma dimensão estritamente social, associado a sobrevivência humana, passando então a ter um caráter de Paisagem Cultural. Desta maneira, seria uma bacia hidrográfica com suas APPs preservadas entendida apenas com um caráter de Paisagem Natural, ou Cultural? Ou ambas? Na verdade as Paisagens Naturais e Culturais dispõem de intensas redes de conexões dinâmicas, as quais mantém 
os elementos inter-relacionados interligados, de maneira sistêmica, cujo funcionamento ocorre também internamente ao recorte espacial de Bacia Hidrográfica.

\section{A DIMENSÃO TERRITORIAL DAS ÁREAS DE PRESERVAÇÃO PERMANENTE}

As APPs podem ser compreendidas também sob o viés territorial, trazendo a essa discussão um caráter estritamente geográfico, uma vez que o conceito de Território faz parte de um dos termos cunhados pela ciência geográfica. Para Raffestin (1993), a construção do território revela relações marcadas pelo poder, sendo assim, faz-se necessário enfatizar como categoria essencial para a compreensão do território o poder exercido por pessoas ou grupos sem o qual o território não se define. Nesse sentido, o território é entendido principalmente numa ênfase político-administrativa, isto é, como o território nacional, espaço físico onde se localiza uma nação; um espaço onde se delimita uma ordem jurídica e política; um espaço medido e marcado pela projeção do trabalho humano com suas linhas, limites e fronteiras.

Segundo Medeiros (2006), áreas protegidas, como no caso das APPs, são áreas territorialmente demarcadas, cuja principal função é a conservação e/ou a preservação de recursos, naturais e/ou culturais, a elas associados. Este autor argumenta que, segundo a União Internacional para a Conservação da Natureza (UICN), elas podem ser definidas como "uma área terrestre e/ ou marinha especialmente dedicada à proteção e manutenção da diversidade biológica e dos recursos naturais e culturais associados, manejados através de instrumentos legais ou outros instrumentos efetivos" (UICN, 1994 apud MEDEIROS, 2006, p.1).

Sua criação pode ser considerada uma importante estratégia de controle de um ambiente já que estabelece limites e dinâmicas de uso e ocupação específicos. Para o autor, este controle e os critérios de uso que normalmente a elas se aplicam são frequentemente atribuídos em razão da valorização dos recursos naturais nelas existentes ou, ainda, pela necessidade de resguardar biomas, ecossistemas e espécies raras ou ameaçadas de extinção. Medeiros (2006) também afirma que a criação de um instrumento de proteção e, por consequência, de novas tipologias de áreas protegidas, reflete tanto as expectativas sociais de grupos interessados quanto os arranjos políticos e institucionais que exercem pressão ou influência sobre o Estado. Uma análise feita sobre a evolução destes instrumentos é, portanto, importante indicador da lógica política e social de criação de áreas protegidas no país e pode auxiliar, sobremaneira, na compreensão da organização e dos objetivos do sistema atual.

\section{ÁREAS DE PRESERVAÇÃO PERMANENTE E MEIO AMBIENTE}

Após reconhecer que APPs possuem caráter geográfico, é preciso também analisa-las sob um viés ambiental, pois este conceito engloba diversos outros temas que transcendem a ciência geográfica e que estão imbricados na legislação ambiental vigente. 
O termo Meio Ambiente pode ser entendido de diversas maneiras. Para Solorzano, Oliveira e Guedes-Bruni (2009), a perspectiva de Meio Ambiente deve suprir a lacuna criada pela forma como as ciências naturais têm tratado o ser humano em suas abordagens, considerando-o como um componente supranatural, dissociado do mundo natural e subtraído no entendimento das resultantes decorrentes de sua interação com o ambiente em que vive. Mendonça (2005) argumenta que, anteriormente às décadas de 1950 e 1960, o conceito de Meio Ambiente era entendido simplesmente como a natureza do planeta com todos os componentes. Esta ideia predominava nas ciências Geográfica, Geológica, Biológica e nas ciências ambientais como um todo. Essencialmente o conceito de Meio Ambiente deve ser compreendido de uma maneira interdisciplinar, portanto o conceito transcende os diversos ramos do conhecimento e exige uma análise integrada, mesmo havendo dificuldades na sua execução.

Portanto, o Meio Ambiente, requer, para sua interpretação, um enfoque que somente se conseguirá através da articulação das diferentes perspectivas disciplinares, e não simplesmente de sua somatória. A abordagem interdisciplinar permite gerar um conhecimento integrado, superando a simples acumulação de enfoques científicos e técnicos (SANTOS, 2012).

A questão ambiental é um campo relativamente novo do conhecimento, surgido na década de 1970, simultaneamente ao início dos movimentos ambientalistas e das conferências mundiais sobre a crise ambiental, nascendo de um objetivo moral. De um modo geral, o papel do Meio Ambiente no contexto científico é o de compreender como a natureza afetou o ser humano e, ao mesmo tempo, como a humanidade afetou o meio ambiente (SOLORZANO; OLIVEIRA; GUEDES-BRUNI, 2009).

Após as grandes guerras mundiais do século passado, os avanços tecnológicos e científicos acarretaram uma diminuição na taxa de mortalidade das pessoas. No entanto, o número de nascimentos não diminuiu proporcionalmente e este fator gerou um grande aumento populacional jamais visto em toda a história (MENDONÇA, 2005). Com isso, começou-se a ter uma maior preocupação com o Meio Ambiente, pois essa mesma população demandava cada vez mais recursos. A partir de então se despertou uma consciência de que esses recursos são finitos e essa consciência implicou em profundas alterações nas relações entre as nações, ou melhor, nas relações entre os países ditos de Primeiro Mundo e os de Terceiro Mundo.

Mendonça (1993) adverte que se observa na atualidade, diante de tão importante desafio, uma forte tendência à utilização, de forma ampla, do termo socioambiental, pois que se tornou muito difícil e insuficiente falar de meio ambiente somente do ponto de vista da natureza, quando se pensa na problemática interação sociedade-natureza do presente, sobretudo no que concerne a países em estágio de desenvolvimento complexo. O mesmo autor ainda coloca que o termo 'sócio' aparece, então, atrelado ao termo ambiental, para enfatizar o envolvimento da sociedade enquanto sujeito dos processos ambientais contemporâneos.

Como mencionado anteriormente, as propostas de se criar as Áreas de Preservação Permanente como mecanismos legais de preservação ambiental vieram da necessidade de 
enfrentamento do desmatamento acerbado dentro do território brasileiro, ou seja, reflexo de uma época em que a temática referente ao meio ambiente começa a ser discutida em escala global.

\section{A FUNCIONALIDADE AMBIENTAL DAS ÁREAS DE PRESERVAÇÃO PERMANENTE}

APPs possuem uma funcionalidade mantenedora das relações geoecológicas do ambiente, como preservar os recursos hídricos e evitar o desenvolvimento de processos erosivos. Magalhães e Ferreira (2000) apud Jarentchuk Jr. (2009) destacam vários aspectos acerca da importância que a vegetação natural possui para manter a estabilidade geopedológica, tais como: evitar a deflagração de processos erosivos em áreas agrícolas ou até mesmo contendo-os; manter a estabilidade do manto pedológico sobre encostas com inclinações acentuadas em função da estruturação da massa de solo em conjunto com a trama radicular, evitando a ocorrência de eventos como os de movimentos de massa; agir como anteparo para o impacto da chuva sobre o solo de maneira a reduzir o efeito de splash, bem como a trama radicular contribui para a manutenção da porosidade dos solos permitindo a infiltração da água e alimentando as colunas freáticas. Essa ação impede o escoamento superficial precoce e a formação de sulcos erosivos que carregam sedimentos aos cursos d'água, aumentando sua turbidez, assoreando-os; por fim, a vegetação contribui também para o equilíbrio do ciclo hidrológico de uma área de drenagem.

Outra importante categoria de APP é a referente às nascentes. Calheiros, Tabai, Bosquilia et al. (2004) destacam que a nascente ideal é aquela que "fornece água de boa qualidade, abundante e contínua, localizada próxima do local de uso e de cota topográfica elevada, possibilitando sua distribuição por gravidade, sem gasto de energia" da mesma forma que, segundo eles, as nascentes preservadas apresentam pontos básicos comuns de controle de erosão do solo em suas estruturas físicas, juntamente com as barreiras vegetais de contenção, além de minimizar a contaminação química e biológica da água. Quanto à ocupação de nascentes, Calheiros, Tabai, Bosquilia et al. (2004) explicam que quando existe a proibição da ocupação da APP de nascente, evita-se os risco de erosão e de contaminação do solo devido as demais atividades agrícolas de preparo do solo, adubação, plantio, cultivos, colheita e transporte dos produtos que levem trabalhadores, máquinas e animais de tração para o local. Para Calheiros et al. (2004), o pisoteio torna a superfície do solo compactado, o que diminui sua capacidade de infiltração, ficando sujeito à erosão laminar e, consequentemente, provocando não só a contaminação da água por partículas do solo, turvando-a, como também, e o que é pior, gerando soterramento da nascente.

Em relação à categoria de matas ciliares, Andrade e Romero (2005) apresentam algumas das suas principais funções: dentre as quais, destaca-se a manutenção do equilíbrio hidrológico por meio: da estabilização das margens do rio através da manutenção do emaranhado de raízes; do controle do aporte de nutrientes e de produtos químicos aos cursos d'água; da filtragem e do controle da alteração da temperatura para o ecossistema 
aquático; da formação de barreiras para o carregamento de sedimentos para os cursos d'água, evitando o assoreamento dos corpos hídricos. Quando um rio não possui mata ciliar fica suscetível a processos erosivos mais frequentes e intensos ao longo de suas margens. Uma das consequências é o assoreamento dos rios que pode causar problemas para as pessoas que vivem próximas das margens degradadas, além de provocar danos às atividades agrícolas e pecuárias, bem como alterar profundamente as relações ecológicas da fauna e flora local.

As matas ciliares também podem formar corredores de biodiversidade aumentando a conectividade da paisagem (METZGER, 2010). Algo extremamente relevante para biomas como o Cerrado e a Mata Atlântica que revelam altíssimas taxas de fragmentação florestal. É cabível salientar que o grau de isolamento está relacionado às chances dos remanescentes serem (re)colonizados, influenciando a probabilidade de extinção local (BROWN; KODRIC-BROWN, 1977) e na perda da variabilidade genética com os fenômenos deletérios de endocruzamento (UEZU; CULLEN JR, 2012).

Marés Mikosik, Nowatzki, Lopes et al. (2010) destacam que, ao se pensar nas categorias de APPs de áreas declivosas, deve-se ter em mente o porquê da sua preservação. Os morros e as montanhas são imprescindíveis para a preservação do ambiente envolvido em função da inclinação (declividade) das suas encostas, pois para ser considerado morro ou montanha, conforme a Lei Florestal Brasileira (BRASIL, 2012), além da sua amplitude altimétrica, pelo menos uma das vertentes deve se encontrar com uma inclinação maior que $25^{\circ}$, ou $46,6 \%$.

A partir dessa visão, os processos erosivos e movimentos de massa são potencialmente maiores nas áreas com altas declividades, principalmente se as encostas estiverem ausentes de vegetação natural e com diferentes graus de ocupação. Nestes casos os processos podem se tornar ainda mais acelerados quando a quantidade de chuvas for mais intensa. O mapeamento dos escorregamentos translacionais realizado na bacia do rio Sagrado, realizado por Marés Mikosik, Nowatzki, Lopes et al. (2010), comprovou que estes se localizam em áreas com altas declividades e solos rasos, sendo que dos oito escorregamentos identificados, sete localizavam-se dentro da delimitação da APP de linha de cumeada (categoria existente na época do mapeamento - BRASIL, 1965), enquanto um estava situado em área de APP referente à declividades acima de $45^{\circ}$, comprovando a importância de se preservar permanentemente essas áreas.

\section{CONSIDERAÇÕES FINAIS}

Na Geografia encontramos os elos entre a história ambiental e a ecologia histórica. Conforme Solorzano, Oliveira e Guedes-Bruni (2009), isso se deve, em parte, à sua ampla abrangência, e ao período de sua sistematização, que buscou a incorporação de uma análise explicativa da dicotomia ser humano-natureza. 
O objetivo deste ensaio não foi o de esgotar todas as funcionalidades ambientais de todas as categorias de APPs. Optou-se por discutir as categorias mais frequentes nos ecossistemas, as matas ciliares, que que integram às diferentes paisagens.

No contexto da legislação ambiental brasileira, discutiu-se a contribuição da Geografia para melhorar a compreensão a respeito de motivos ou fatores que justificam ou mesmo exigem a manutenção de APPs. Também traz o questionamento de quanto essa manutenção, ou preservação propriamente dita é essencial para que os ecossistemas continuem exercendo a sua contribuição para o desenvolvimento da sociedade. Sobretudo pelo importante papel que a manutenção de APPs exerce no que concerne à redução da suscetibilidade a deflagração de processos erosivos, pensando no efeito desses processos sobre os corpos hídricos.

\section{REFERÊNCIAS}

ACE. Auditoria, Consultoria e Educação Ambiental Ltda. EIA (Estudo de Impacto Ambiental) da Melport Terminais Marítimos Ltda. Pontal do Paraná, 2014.

ACE. Auditoria, Consultoria e Educação Ambiental Ltda. EIA (Estudo de Impacto Ambiental) do Novo Porto Terminais Portuários Multicargas e Logística Ltda. Paranaguá, 2013.

ALMEIDA, A.M.; PAULA, E.V.; KLEINA, M. Avaliação das modificações do Código Florestal Brasileiro na bacia do rio Sagrado (Morretes - PR). In: SIMPÓSIO LATINO - AMERICANO DE GEOGRAFIA FÍSICA/ SIMPÓSIO IBERO-AMERICANO DE GEOGRAFIA FÍSICA, 8, 4, 2014. Santiago. Resumos...

ANDRADE, L.M.S.; ROMERO, M.A.B. A importância das áreas ambientalmente protegidas nas cidades. In: ENCONTRO NACIONAL DE PÓS-GRADUAÇÃO E PESQUISA EM PLANEJAMENTO URBANO E REGIONAL - ANPUR. 11, 2005, Salvador. Resumos...

BERTRAND, G. Paisagem e Geografia Física global. Esboço metodológico. Rev. RA'E'GA, Curitiba, n. 8, p. 141-152, 2004.

BRASIL. Lei Federal no 4771, de 15 de setembro de 1965. Diário Oficial [da] da República Federativa do Brasil. Brasília: Congresso Nacional, 2012.

Lei Federal $\mathbf{n}^{\mathbf{0}}$ 12.727, de 17 de outubro de 2012. Diário Oficial [da] da República Federativa do Brasil. Brasília: Congresso Nacional, 2012.

BROWN, J. W.; KODRIC-BROWN, A. Turnover rates in insular biogeography: effect of immigration on extinction. Ecology, n. 58, p. 445-449, 1977.

CALHEIROS, R. O.; TABAI, F. C. V.; BOSQUILIA, S. V.; CALAMARI, M. Preservação e recuperação das nascentes (de água e de vida). Comitê das Bacias Hidrográficas dos Rios Piracicaba, Capivarí e Jundiaí. Piracicaba: CTRN, 2004.

CHRISTOFOLETTI, A. Geomorfologia. 2.ed. São Paulo: Edgard Blucher, 1980.

COELHO NETTO, A.L. Hidrologia de Encosta na Interface com a Geomorfologia. In: GUERRA, A. J. T.; CUNHA, S. B. (Orgs.). Geomorfologia: uma atualização de bases e conceitos. 7.ed. Rio de Janeiro: Bertrand Brasil, 2007.

CUNHA, S.B.; GUERRA, A.J.T. Degradação Ambiental. In: CUNHA, S. B.; GUERRA, A. J. T. (Orgs) Geomorfologia uma atualização de bases e conceitos. 4.ed. Rio de Janeiro: Bertrand Brasil, 2003.

DEVELEY, P.F.; PONGILUPPI, T. Impactos potenciais na avifauna decorrentes das alterações propostas para o Código Florestal Brasileiro. Biota Neotropica, Campinas, v. 10, n. 4, p. 43-45, Dec. 2010.

JARENTCHUKJR, O. Diagnóstico morfodinâmico para a delimitação de áreas prioritárias à recuperação e 
conservação ambiental na bacia hidrográfica do rio Cachoeira - Antonina/PR. Curitiba, 2009. Monografia (Curso de Bacharel em Geografia) - Universidade Federal do Paraná.

LEFF, E. Epistemologia ambiental. São Paulo: Cortez, 2001.

MARÉSMIKOSIK, A.P.; NOWATZKI, A.; LOPES, F.C.A.;PAULA, E.V.;SANTOS, L.J.C.;SANTOS, I. Análise integrada das ocorrências dos escorregamentos translacionais rasos na bacia hidrográfica do rio Sagrado (Morretes-PR). In: SIMPÓSIO BRASILEIRO DE CARTOGRAFIA GEOTÉCNICA E GEOAMBIENTAL, 7, 2010, Maringá. Resumos...

MEDEIROS, R. Evolução das tipologias e categorias de áreas protegidas no Brasil. Rev. Ambiente \& Sociedade, v.9, n.1. p.41-64, 2006.

MENDONÇA, F. de A. Diagnóstico ambiental de microbacia hidrográfica: proposição metodológica na perspectiva do zoneamento planejamento e gestão ambiental. Rev. RA'E'GA, Curitiba, n. 3, p.67-89, 1993.

Geografia e meio ambiente. 8.ed. São Paulo: Contexto, 2005.

METZGER, J.P. O Código Florestal tem base científica? Natureza \& Conservação, v. 8, n. 1, p. 92-99, 2010.

NOWATZKI, A.; SANTOS, L.J.C.; PAULA, E.V. Utilização do SIG na delimitação das áreas de preservação permanente (APPs) na Bacia do Rio Sagrado (Morretes/PR). Sociedade \& Natureza, v. 22, p. 121-134, 2010.

NOWATZKI, A.; SANTOS, L.J.C. Relações entre a geopedologia e as áreas de preservação permanente nas bacias hidrográficas dos rios Alto Cachoeira e Sagrado, Estado do Paraná, Brasil. Geomorfologia 2010, Cidade do Porto, v. 7, p. 29-39, 2012.

PAULA, E.V.; GUIMARÃES, J.; IBAIXE, D.R. Estimativa da Produção de Sedimentos e Análise de Cenários das Áreas Prioritárias à Recuperação Ambiental na Bacia Hidrográfica do rio Jaguari (MG/SP). Revista Continentes, v. 5, n.4, p. 23-44, 2014.

PAS. Planejamentos Agroecológicos Sponholz S/A. Plano Municipal de Gestão de Recursos Hídricos) do Município de Cerro Azul/PR. Curitiba, 2009.

RAFFESTIN, C. Por uma Geografia do Poder. São Paulo: Ática, 1993.

ROSS, J. L. S. Geomorfologia aplicada aos EIAs-RIMAs. In: GUERRA, A J.T.; CUNHA, S.B. (Orgs). Geomorfologia e meio ambiente. 4.ed. Rio de Janeiro: Bertrand Brasil, 2003.

SANTOS, E.C. Geografia, educação ambiental e complexidade frente aos desafios do mundo contemporâneo. Rev. Geonorte, v.4, n.4, p.155-174, 2012.

SANTOS, W C.; BOLDRINI, E.B. Recuperação de Mata Ciliar na Floresta Atlântica: Projeto RAPPs utilizando técnicas de sistemas agroflorestais. Antonina: ADEMADAN, 2012.

SCHIER, R.A. Trajetórias do conceito de Paisagem na Geografia. Rev. RA'E'GA, Curitiba, n. 7, p. 79-85, 2003.

SOLORZANO, A.; OLIVEIRA, R.R.; GUEDES-BRUNI, R.R. Geografia, história e ecologia: criando pontes para a interpretação da paisagem. Ambiente \& Sociedade, Campinas, v. 12, n. 1, p. 49-66, 2009.

SOTCHAVA, V.B. Estudos dos Geossistemas: método em questão. São Paulo: IGEO/USP, 1976.

TRICART, J. Ecodinâmica. Rio de Janeiro: IBGE, 1977.

UEZU, A.; CULLEN JR., L. Da fragmentação florestal à restauração da paisagem: aliando conhecimento científico e oportunidades legais para a conservação. In: PAESE, A.; UEZU, A.; LORINI, M.L.; CUNHA, A. (Orgs.) Conservação da Biodiversidade com SIG. São Paulo: Oficina de Textos, 2012.

UFPR. Universidade Federal do Paraná. Departamento de Geografia. Diagnóstico de subsidio ao Plano de Manejo da APA Federal de Guaraqueçaba: Etapa Tagaçaba. Curitiba, 2014. 150 p. Relatório técnico.

VARJABEDIAN, R.; MECHI, A. As APPs de Topo de Morro e a Lei12.651/12. In: CONGRESSO BRASILEIRO DE GEOLOGIA DE ENGENHARIA AMBIENTAL, 14, 2013, Rio de Janeiro. Anais ... 